\title{
Cyclic shear response of fibre-reinforced cemented paste backfill
}

\author{
L. FESTUGATO*, A. FOURIE† and N. C. CONSOLI*
}

\begin{abstract}
In order to investigate techniques to improve tailings backfill stability in stopes, the cyclic shear response of fibre-reinforced cemented mine tailings was studied. Cyclic simple shear tests were conducted on fibre-reinforced and non-reinforced cemented mine tailings. The tailings, produced from gold mining, are classified as sandy silt with traces of clay. Portland cement (5\%) and polypropylene fibres (zero and $0.5 \%$ ) were added to the material. Under monotonic shear conditions, the addition of fibres confers hardening behaviour to the cemented material. Under shear strain controlled cyclic conditions, fibres increased the shear stress values of the cemented samples after successive load cycles. The agreement of the strength envelopes of both monotonic and cyclic stress paths, under different cyclic loading conditions, allows the use of the same strength parameters of mixtures analysed under different loading conditions.
\end{abstract}

KEYWORDS: reinforced soils

ICE Publishing: all rights reserved

\section{NOTATION}

$C_{\mathrm{c}}$
$C_{\mathrm{u}}$
$d_{\text {tex }}$
$d_{10}$
$d_{50}$
$G_{\mathrm{s}}$
$\gamma$
$\Delta u$
$\sigma_{\mathrm{v} \text { initial }}^{\prime}$
$\sigma_{\mathrm{v}}^{\prime}$
$\tau$
$\tau_{\text {cyc } \max }$
$\tau_{\text {cyc } \max } / \sigma_{\mathrm{v} \text { initial }}^{\prime}$

coefficient of curvature

coefficient of uniformity

unit of measure for linear mass density of fibres $(\mathrm{g} / 10000 \mathrm{~m})$

effective diameter

mean diameter

specific gravity

shear strain

pore pressure increment

initial effective vertical stress

effective vertical stress

shear stress

cyclic maximum shear stress

maximum cyclic shear stress to initial effective vertical stress ratio

\section{INTRODUCTION}

Paste backfill is the process whereby full stream tailings are combined with small amounts of cement and water before being used to fill previously mined voids in an open stope mining situation. In order to contain the material in a stope (i.e. stopping it from flowing into nearby mine workings), containment barricades are constructed in the stope drawpoint (Helinski et al., 2007).

The mining process usually includes exposure of a face of these stopes, which can reach heights of over $80 \mathrm{~m}$ in many cases. The backfill therefore has to be selfsupporting as well as able to resist dynamic loading, should it occur. The potential for dynamic loading to

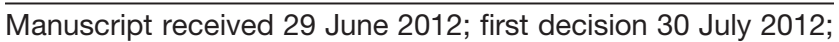
accepted 10 December 2012.

Published online at www.geotechniqueletters.com on 15 January 2013.

*Department of Civil Engineering, Federal University of Rio Grande do Sul, Porto Alegre, Brazil

$\dagger$ Department of Civil and Resource Engineering, The University of Western Australia, Perth, Australia induce liquefaction is usually only a concern during the first few days after placement because, thereafter, the selfdesiccation process (Helinski et al., 2007) results in development of negative pore water pressures. Failures of backfilled stopes are not unknown. Between December 2003 and December 2004, there were reportedly at least six paste fill barricade failures worldwide, with each of these failures resulting in an inrush of fill to the mine workings (Helinski et al., 2006).

It is now well known that randomly distributed tensile inclusions, such as polypropylene fibres, incorporated into soils improve their mechanical behaviour (e.g. Consoli et al., 2009, 2010a, 2011a, 2011b) and could potentially improve cemented paste backfill (CPB) shear response. The relevant mechanism is that the stress is transferred from the soil to the tensile inclusions, mobilising their tensile strength and imparting this resisting force to the soil, thus leading to an improvement in load-carrying capacity of the material. Consoli et al. (2010a) showed that fibre insertion causes an increase in the unconfined compression strength of a cemented silty sand. However, the influence of fibre inclusion on the mechanical behaviour of CPBs has not been previously discussed. CPB material is significantly different from conventional reinforced cemented sand - it usually has a wider particle size distribution (because full plant tailings are used), it has a lower solids content than natural or compacted sands (because it is placed hydraulically) and it is likely to be subjected to significantly higher shear stresses as a consequence of the exposure of high vertical faces, as mentioned earlier.

According to Wijewickreme et al. (2005), the preponderance of laboratory studies on mine tailings has not been performed using cyclic simple shear equipment and the studied stress paths therefore do not simulate the cyclic rotation of principal stresses that takes place during earthquake loading. Previous studies (Arthur et al., 1980; Wijewickreme \& Vaid, 1993) showed that most soils experience deformations due to changes in the magnitudes of principal stresses and also to changes in their directions. The variation of shear stresses under cyclic conditions 


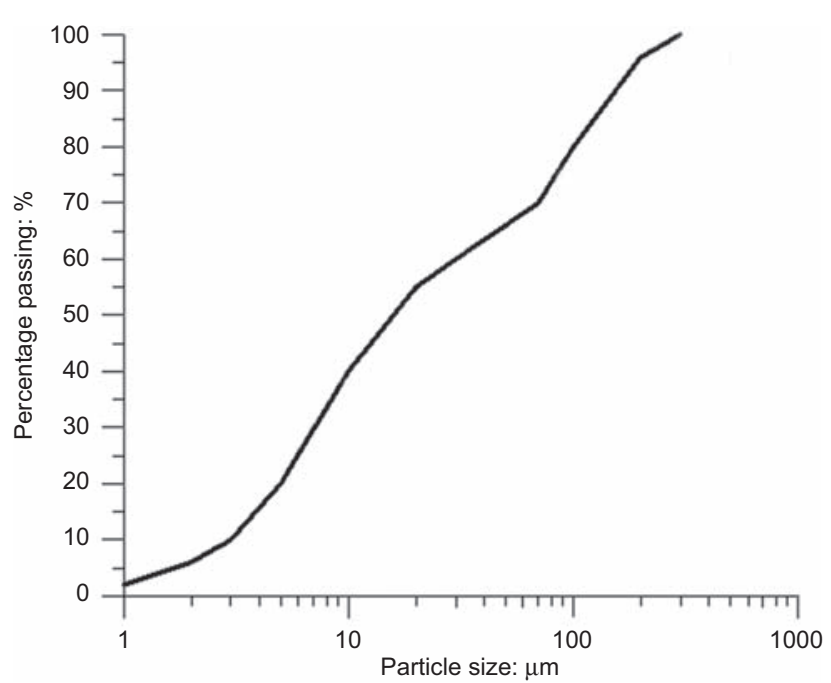

Fig. 1. Particle size distribution of mine tailings

along with changes in the direction of principal stresses is achieved during cyclic direct simple shear tests (Wijewickreme et al., 2005). Vaid \& Finn (1979) considered the direct simple shear test as the most appropriate for the simulation of earthquake loading conditions. Therefore, through a series of undrained cyclic direct simple shear tests results, the fibre reinforcement of a $\mathrm{CPB}$ was evaluated to further understand the cyclic response of fibre-reinforced cemented mine tailings.

\section{MATERIALS AND METHODS \\ Mine tailings}

The studied tailings, produced from gold mining, are classified as sandy silt with traces of clay. The particle size distribution of the material is presented in Fig. $1\left(d_{10}=\right.$ $\left.3 \mu \mathrm{m}, d_{50}=17 \mu \mathrm{m}, C_{\mathrm{u}}=10, C_{\mathrm{c}}=0.63\right)$. The specific gravity $\left(G_{\mathrm{s}}\right)$ of the material is 2.72 and its mineralogical composition is presented in Table 1.

\section{Cement}

For sample preparation, general Portland cement (Type II) was used as the cementing agent. The cement content, defined as the mass of dry cement divided by the dry mass of soil, was $5 \%$. The use of $5 \%$ of cement was chosen considering international experience with cemented soils (Consoli et al., 2007, 2010b; Mitchell, 1981). This is the value used in all production backfilling of stopes at the mine site from which the tailings were obtained.

\section{Fibres}

Monofilament polypropylene (extensible) fibres were used to reinforce the cemented mine tailings. Their average (a)

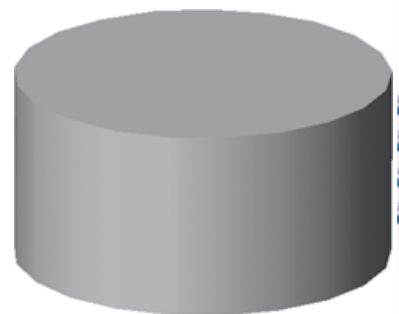

(c)
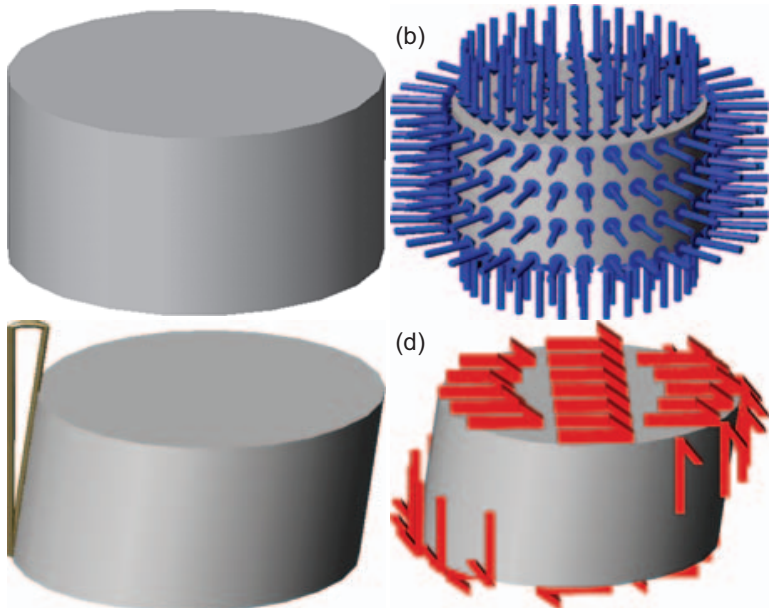

(e)

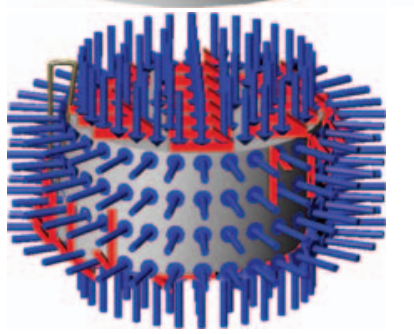

(d)

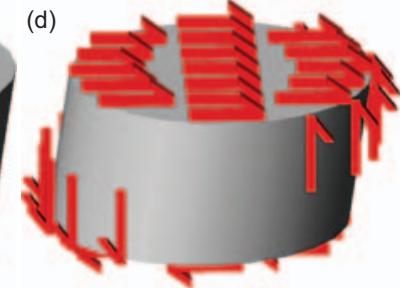

Fig. 2. Schematic illustration of direct simple shear test procedure: (a) sample prior to test; (b) consolidation; (c) shear strain application; (d) shear stress measurement; (e) 'actual' conditions imposed on sample

dimensions were $50 \mathrm{~mm}$ length and $0 \cdot 1 \mathrm{~mm}\left(d_{\text {tex }}=100\right)$ diameter, with a specific gravity of $0 \cdot 91$, tensile strength of $120 \mathrm{MPa}$, elastic modulus of $3 \mathrm{GPa}$ and linear strain at failure of $80 \%$. The fibre content used in the experiments was $0.5 \%$ by weight of dry solids. Previous studies (Consoli et al., 2004, 2009, 2011b) have shown that these fibre characteristics optimise workability and improve the mechanical behaviour for different types of soil. As no other study has ever been carried out on fibre-reinforced mine tailings, these characteristics were taken as the initial reference, and worked satisfactorily. Technically, the amount chosen is applicable in a real situation as it has been applied by Consoli et al. (2012) in a pilot treatment in the field.

\section{The direct simple shear test}

The direct simple shear test is well known and widely used for measuring the strength and stiffness of soil. It is preferred by some because it is the only laboratory test that subjects a soil sample to constant-volume plane-strain conditions and allows principal stress rotation - conditions that are often representative of stress states in typical field situations such as the mode of shearing adjacent to a pile shaft (Randolph \& Wroth, 1981) or under an offshore

Table 1. Chemical composition of the studied mine tailings

\begin{tabular}{l|l|r}
\hline Mineral & Chemical composition & Amount: \% \\
\hline Quartz & $\mathrm{SiO}_{2}$ & 29 \\
Muscovite & $\left(\mathrm{K}, \mathrm{Na}_{2} \mathrm{Al}_{2}(\mathrm{Si}, \mathrm{Al})_{4} \mathrm{O}_{10}(\mathrm{OH})_{2}\right.$ & 24 \\
Albite & $\mathrm{NaAlSi}_{3} \mathrm{O}_{8}$ & 25 \\
Calcite & $\mathrm{CaCO}_{3}$ & 1 \\
Dolomite & $\left.\mathrm{CaMg}_{2} \mathrm{CO}_{3}\right)_{2}$ & 17 \\
Orthoclase & $\mathrm{KAlSi}_{3} \mathrm{O}_{8}$ & 4 \\
\hline
\end{tabular}


gravity-base platform (Andresen et al., 1979). Doherty \& Fahey (2011) describe the distinct direct simple shear test apparatus used and available worldwide.

The results obtained in the present work were obtained using a UWA-type simple shear apparatus (Mao \& Fahey, 2003). In this type of apparatus, to impose plane-strain conditions, the sample height is fixed, which, coupled with the constant-volume conditions imposed by the pore fluid, prevents any change in cross-sectional area (Doherty \& Fahey, 2011). Figure 2 shows a schematic illustration of the test procedure with the conditions imposed on the sample.

\section{Sample preparation and test procedure}

The weights of moist mine tailings and cement necessary for sample preparation were determined with an accuracy of $0.01 \mathrm{~g}$. The two materials were mixed in a mechanical blender for about $10 \mathrm{~min}$. When employed, the mass of fibres was determined with an accuracy of $0.001 \mathrm{~g}$ and manually incorporated into the cement-backfill mixture after its preparation. The mixtures were prepared in amounts to produce the samples and allow two measurements of moisture content. The moisture content after treatment was always similar, approximately $28 \cdot 5 \%$. The mix was then poured into disposable plastic moulds and placed inside a humidity chamber at $22 \pm 2{ }^{\circ} \mathrm{C}$, where they remained for 14 days before the test. As the samples were prepared in saturated condition and the moisture content was similar, all specimens' unit weight was similar, approximately $19.7 \mathrm{kN} / \mathrm{m}^{3}$. The samples were produced to dimensions of $102 \mathrm{~mm}$ diameter and $102 \mathrm{~mm}$ height to achieve the minimum ratio between the smallest sample dimension and the largest fibre dimension of 2. Immediately prior to testing, the samples were stripped from the moulds and, using a thin-walled hollow cylinder, reduced to dimensions of $100 \mathrm{~mm}$ diameter and $50 \mathrm{~mm}$ height. They
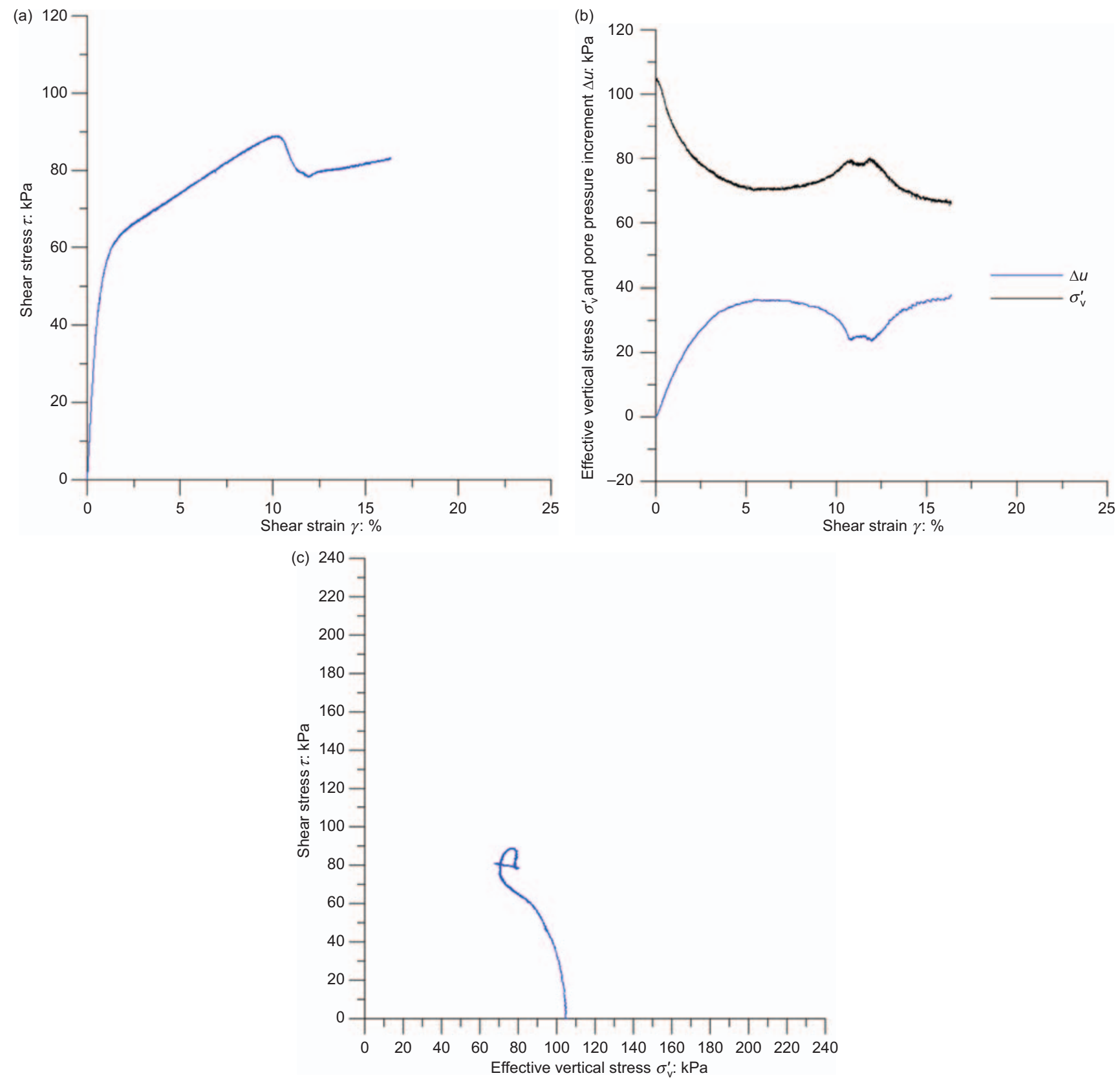

Fig. 3. Monotonic shear response of non-reinforced cemented mine tailings under $100 \mathrm{kPa}$ of initial effective vertical stress 
were then placed in the equipment, where a latex membrane was used to allow application of back pressure.

The test procedure involves placing the sample between rigid cylindrical top and bottom heads with edge protuberances to ensure adequate sample fitting. A thin latex membrane $(0.5 \mathrm{~mm})$ envelops the sample. Consolidation pressures are radially applied through the membrane by increasing confining pressure, and vertically through the head. Thus, independent control of horizontal and vertical stresses is allowed, as in triaxial testing.

The stages of the direct simple shear test are similar to those of a triaxial test. Initially, a flow of water is established through the sample to expel possible air bubbles. Increments of confining pressure and back pressure are then applied to the sample up to a satisfactory $B$ parameter (at least 0.97; Skempton (1954)). The sample is consolidated and, finally, shearing is started.

\section{RESULTS}

Monotonic shear response

Monotonic simple shear tests were carried out to establish a reference for comparison with the cyclic results. The tests were performed under undrained conditions with a displacement rate of $0.1 \mathrm{~mm} / \mathrm{min}$, equivalent to a constant shear strain rate of about $0 \cdot 2 \% / \mathrm{min}$.

Figure 3 presents the monotonic shear test results for non-reinforced material. For $100 \mathrm{kPa}$ of initial effective vertical stress, the non-reinforced cemented matrix presented a peak shear stress of about $90 \mathrm{kPa}$ around $11 \%$ shear strain. There is a pore pressure increase of about $40 \mathrm{kPa}$ and a vertical effective stress reduction of the same magnitude.

The monotonic shear test results for fibre-reinforced material are shown in Fig. 4. The addition of fibres to artificially cemented mine tailings confers on the material a

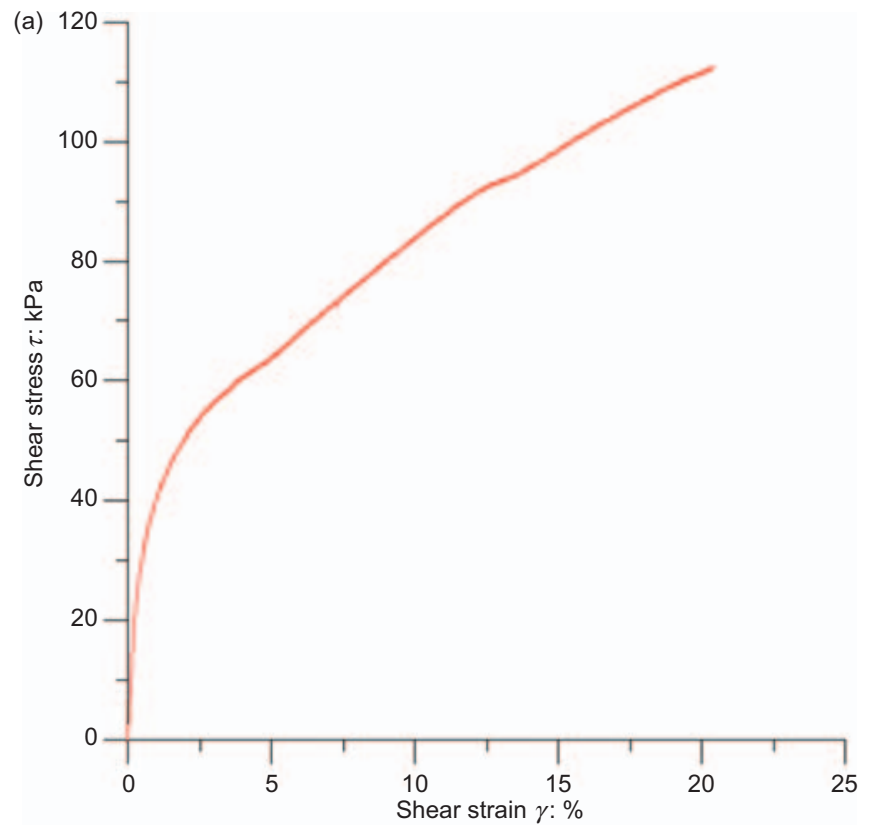

(c) 240

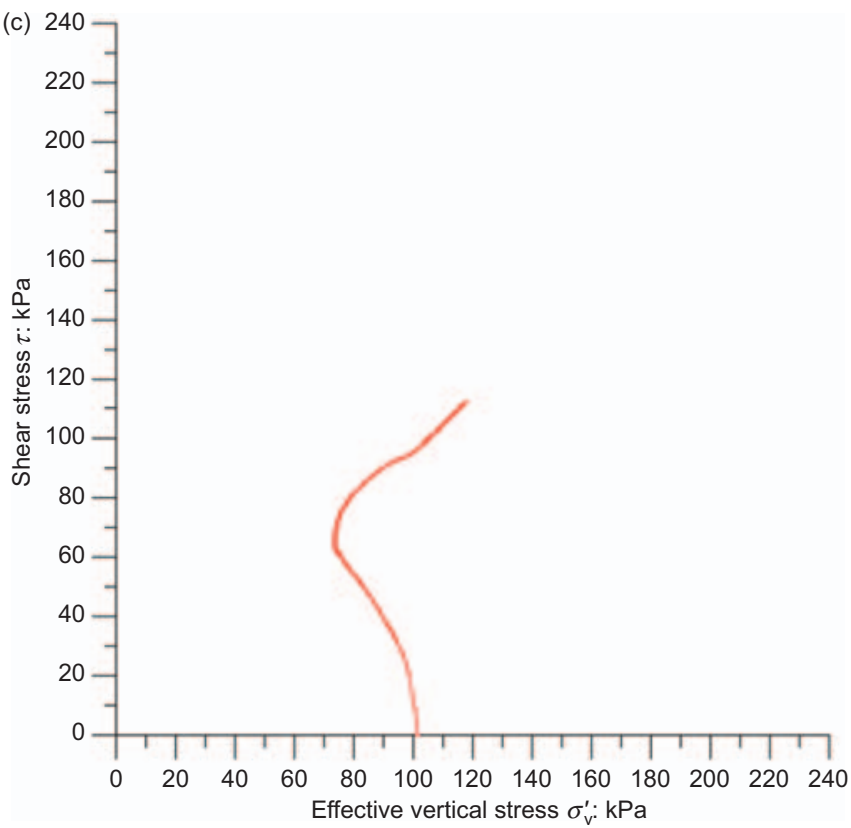

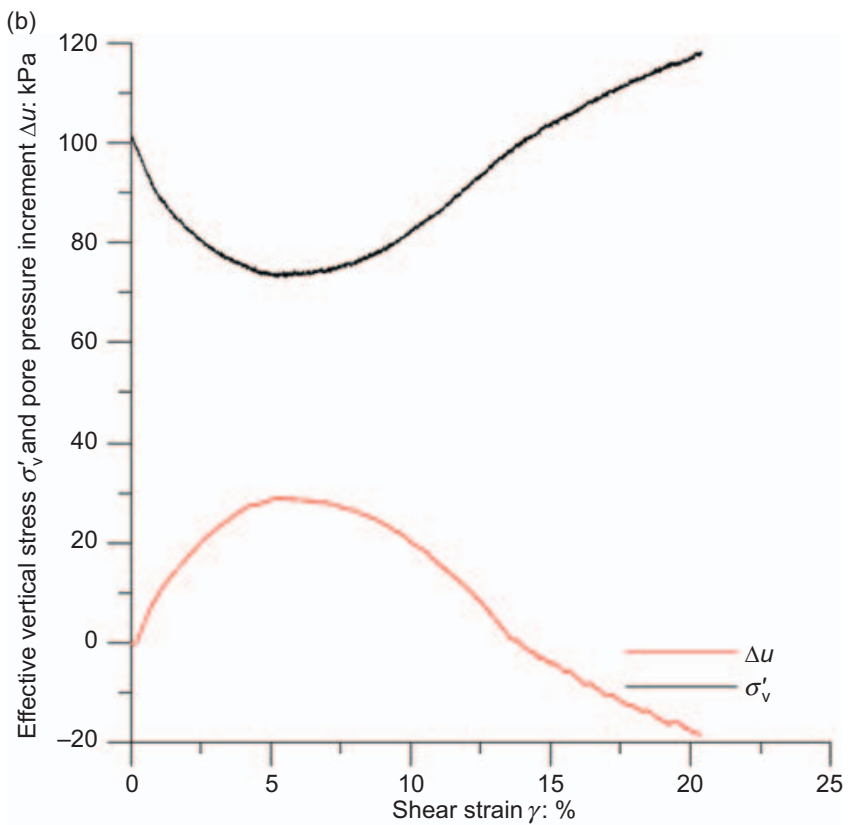



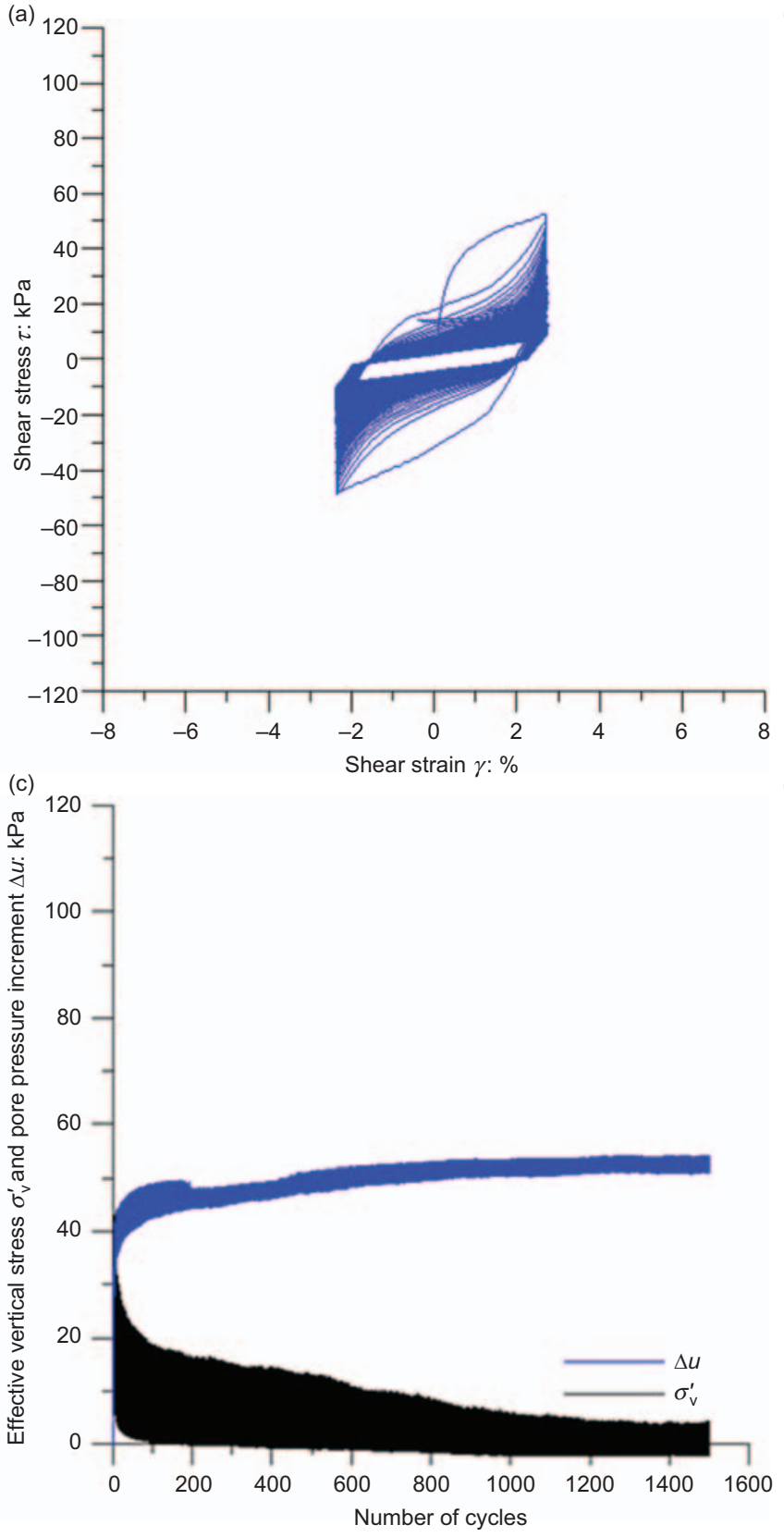

(b)

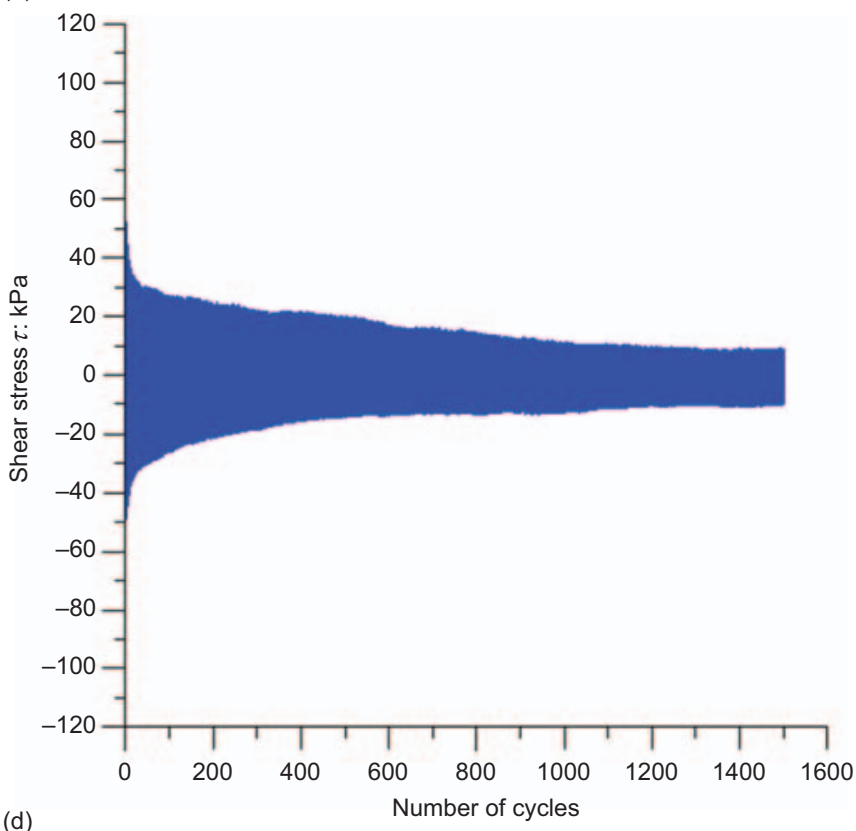

(d)

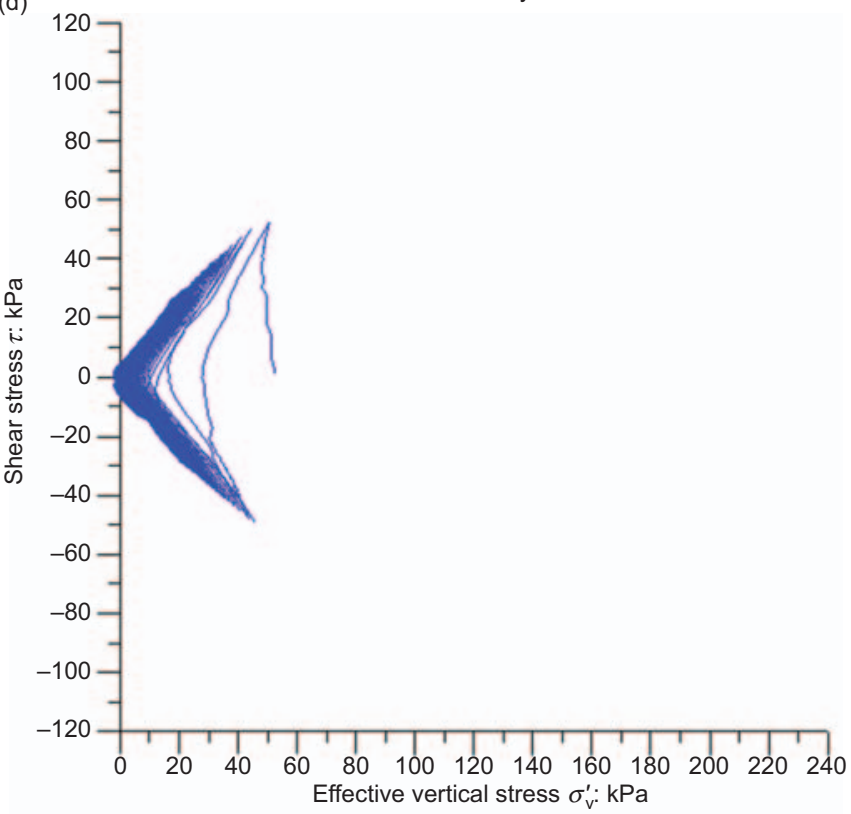

Fig. 5. Cyclic shear response of non-reinforced cemented mine tailings under $50 \mathrm{kPa}$ of initial effective vertical stress and $\pm 2 \cdot 5 \%$ of controlled shear strain

very pronounced hardening behaviour, which provides for higher shear deformation and greater strength. For 20\% shear strain, the shear stress was about $110 \mathrm{kPa}$. Furthermore, the values of pore pressure increments and effective vertical stress reductions reach a threshold, around $30 \mathrm{kPa}$, where the prior compression trend changes to expansion up to the end of the test.

\section{Strain controlled cyclic shear response}

The strain controlled cyclic simple shear tests were also performed under undrained conditions. The same frequency of $0 \cdot 1 \mathrm{~Hz}$ was used for all cyclic tests. Under such conditions, the equipment imposes a specified displacement and, as the main response, measures the values of shear stresses. The tests were terminated only when the limit of the data acquisition system (1500 cycles) was achieved.
Figure 5 shows the results of the cyclic test on the nonreinforced cemented mine tailings sample under an initial effective vertical stress of $50 \mathrm{kPa}$ and controlled shear strain $(\gamma)$ of $\pm 2 \cdot 5 \%$.

Strain controlled cyclic simple shear tests were also carried out on non-reinforced CPB samples under $100 \mathrm{kPa}$ of initial effective vertical stress and controlled shear strains of $\pm 2 \cdot 5 \%, \pm 4 \cdot 5 \%$ and $\pm 7 \cdot 0 \%$. Figure 6 summarises these results. The increase of initial effective vertical stress, as expected, increases the shear strength. The increase of imposed shear strain increases the shear stress values achieved in the initial load cycles, to the detriment of the reduced levels of shear stresses for the later cycles. The composite develops greater strength by deforming more and, the higher the strain level, the greater the damage to the cemented matrix structure. Over successive load cycles, the shear strength decreases gradually and, for later cycles, is higher for lower strain levels. 

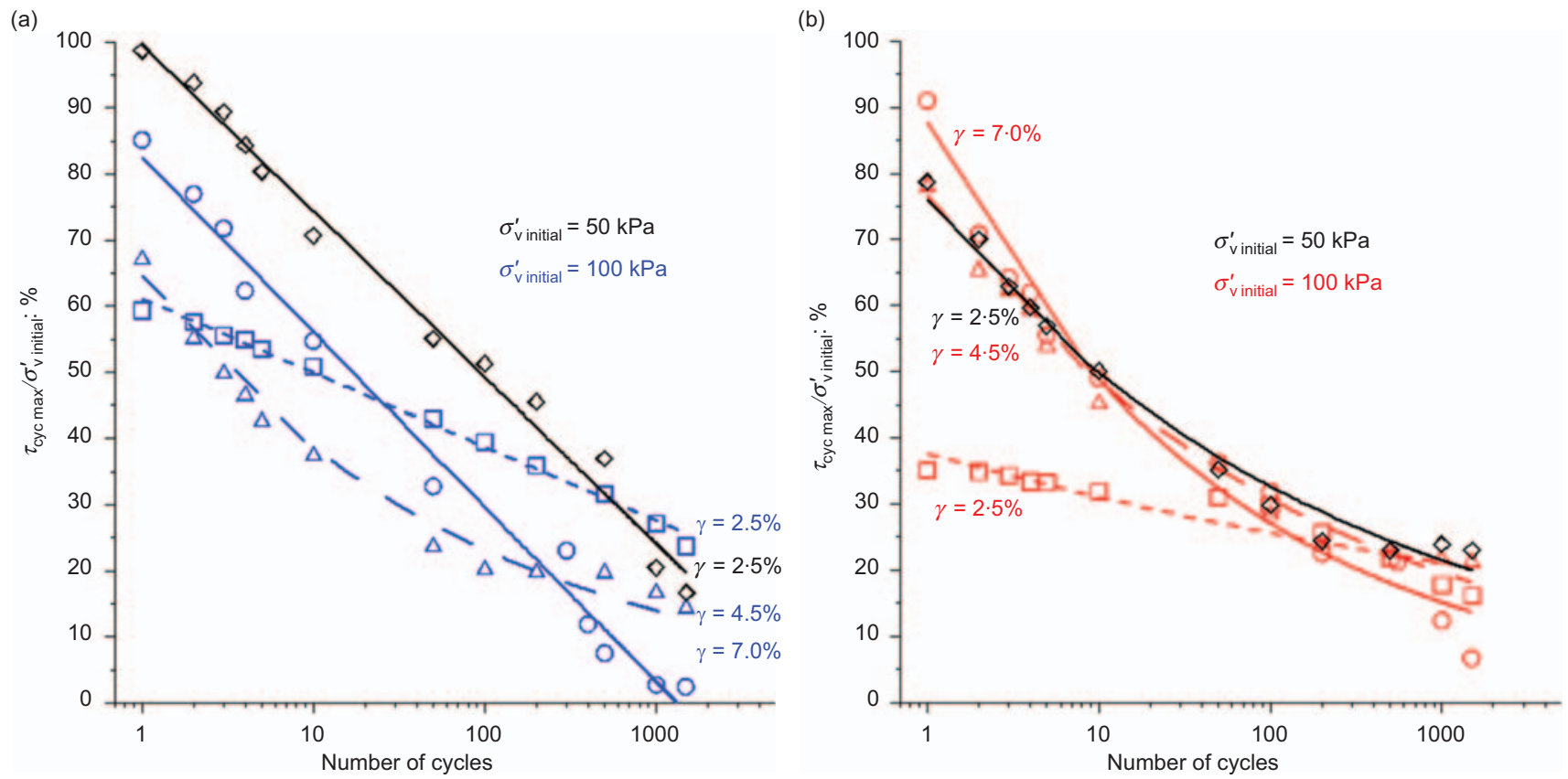

Fig. 6. Ratio of cyclic maximum shear stress to initial effective vertical stress $\tau_{\text {cyc max }} / \sigma_{\mathrm{v}}^{\prime}$ initial versus number of cycles of strain controlled tests under $100 \mathrm{kPa}$ and $50 \mathrm{kPa}$ of initial effective vertical stress for non-reinforced cemented mine tailings (a) and fibrereinforced cemented mine tailings $(b)$

Figure 7 shows the results of the cyclic test on the reinforced cemented mine tailings sample under an initial effective vertical stress of $50 \mathrm{kPa}$ and controlled shear strain $(\gamma)$ of $\pm 2 \cdot 5 \%$. Strain controlled cyclic simple shear tests were also carried out on reinforced $\mathrm{CPB}$ samples under $100 \mathrm{kPa}$ of initial effective vertical stress and controlled shear strains of $\pm 2 \cdot 5 \%, \pm 4 \cdot 5 \%$ and $\pm 7 \cdot 0 \%$. Figure 7 summarises the results from these tests. The increase of initial effective vertical stress, as expected, increases the shear strength. The increase of shear strain levels again increases the shear stress values achieved in the initial load cycles, to the detriment of the reduced levels of shear stresses for the later cycles.

\section{Cyclic shear behaviour comparison}

Comparison of the cemented samples' cyclic behaviour was performed by normalising the maximum cyclic shear stresses $\left(\tau_{\text {cyc max }}\right)$ by the initial effective vertical stress of each test $\left(\sigma_{\mathrm{v}}^{\prime}\right.$ initial $)$.

For each test, with a different strain imposed during shearing, curves were adjusted to relate the ratio of maximum cyclic shear stress and the initial effective vertical stress $\left(\tau_{\text {cyc } \max } / \sigma_{\mathrm{v}}^{\prime}\right.$ initial $)$ with the number of cycles. Figure 6(a) groups such curves for the tests carried out under the initial effective vertical stress of $100 \mathrm{kPa}$ and $50 \mathrm{kPa}$ on non-reinforced cemented mine tailings and Fig. 6(b) on fibre-reinforced cemented mine tailings.

For the higher strain levels of $\pm 4 \cdot 5 \%$ and $\pm 7 \cdot 0 \%$, the fibre addition slightly increased $\tau_{\text {cyc } \max } / \sigma_{\mathrm{v}}^{\prime}$ initial from the start of the termination point when compared with the nonreinforced material. For the lowest studied strain level of $\pm 2 \cdot 5 \%$, the addition of fibres caused a stress ratio reduction for the initial cycles but did not affect the stress ratio values for the later cycles as compared with the nonreinforced material. As for static loads, the fibre reinforcement performance is more effective for higher cyclic strain levels.
The increase of shear strain levels increases the shear stress values achieved in the initial load cycles, to the detriment of the reduced levels of shear stresses for the later cycles. For the first cycles, the reinforced sample develops greater strength by deforming more and, for the final cycles, the higher the strain level, the greater the damage to the cemented matrix structure. Over successive load cycles, the shear strength decreases gradually and, as shown in Fig. 6, for the later cycles, is higher for lower strain levels. However, for the later cycles, the shear stress values of the fibre-reinforced cemented material, for different strain levels, are similar. The damage to the cemented bonds is compensated by the existence of fibres that absorb and redistribute the loads.

\section{Stress paths and strength envelopes}

From the simple shear tests results, the strength envelopes of the different materials and their strength parameters are defined. For comparison, the stress paths of monotonic and cyclic tests are grouped, as well as the strength envelopes. The stress paths are presented and the strength envelopes are defined in the effective vertical stress $\left(\sigma_{\mathrm{v}}^{\prime}\right)$ and shear stress $(\tau)$ space. Thus, the effective friction angle can be directly determined from the slope of the strength envelope and the cohesive intercept from the intercept of the envelope with the axis of the shear stress.

Figure 8 presents such an analysis for both the nonreinforced cemented mine tailings (Fig. 8(a)) and the fibrereinforced cemented mine tailings (Fig. 8(b)). The stress paths of the tests performed under distinct load conditions - monotonic and cyclic - reach the same strength envelopes. The effective internal friction angle of the nonreinforced material is $49^{\circ}$ and that of the reinforced material is $45^{\circ}$. The cohesion intercept of both materials is zero.

The agreement of the same strength envelopes to stress paths of monotonic and cyclic tests is remarkable. 
(a)

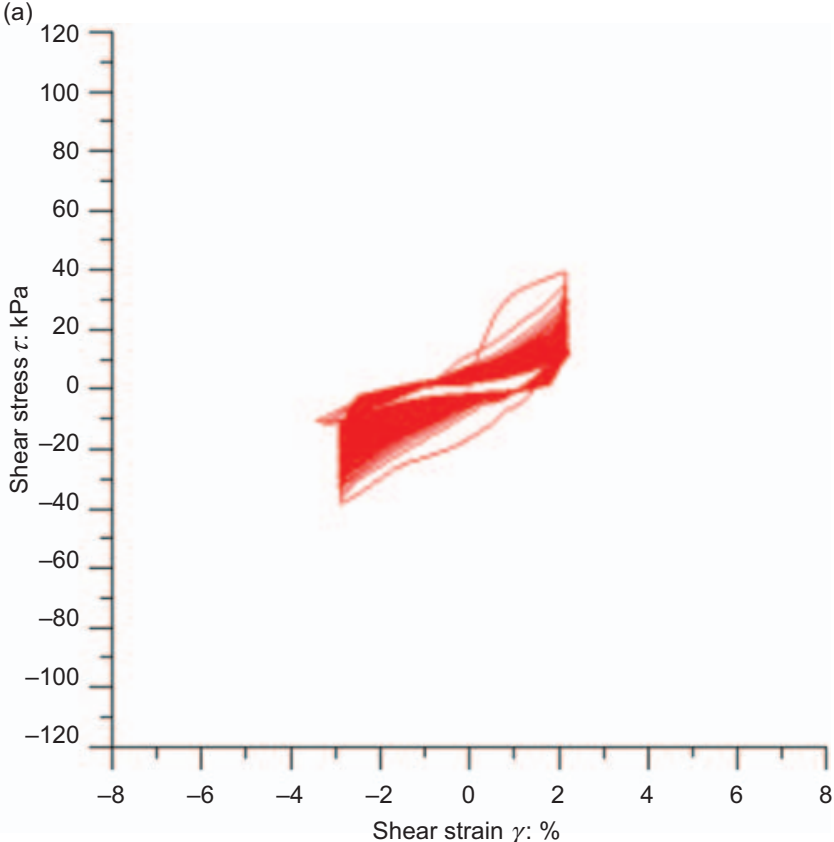

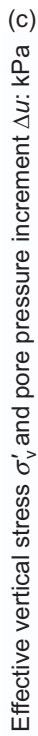

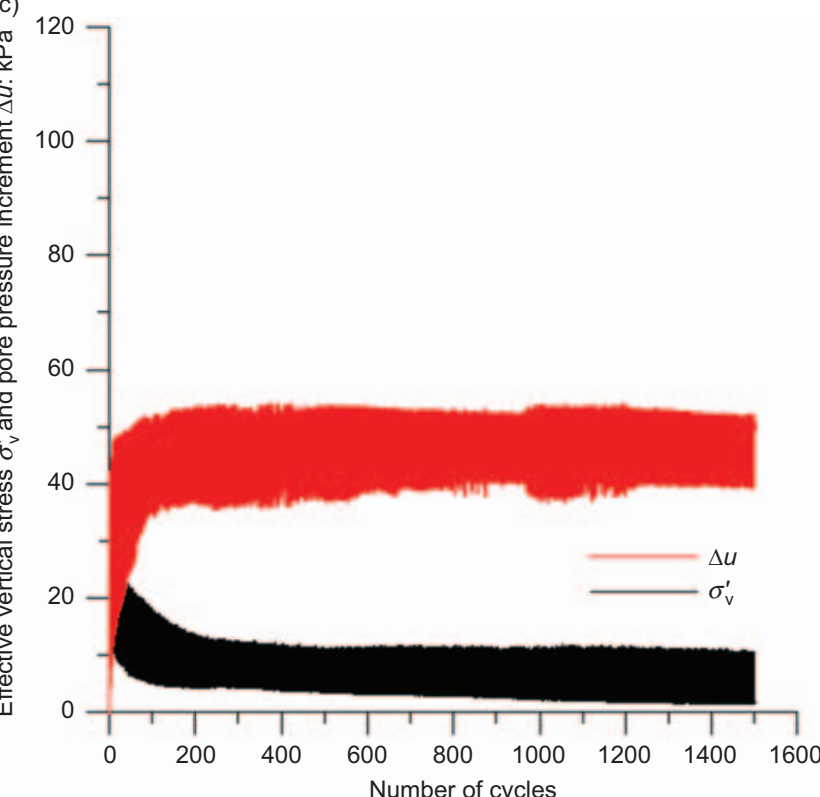

(b)

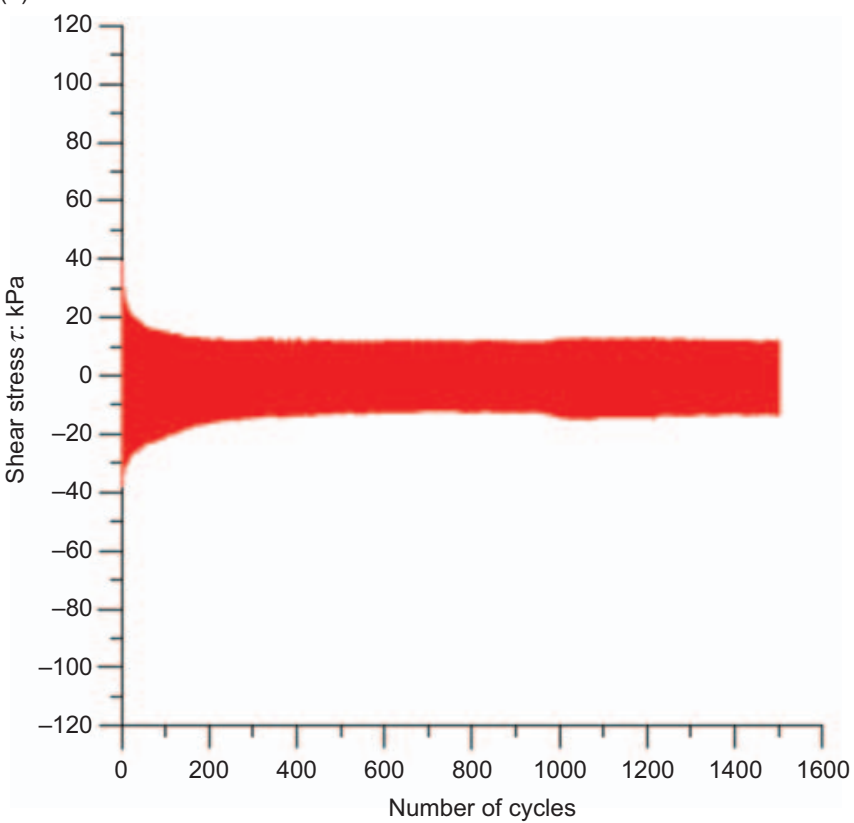

(d) 120

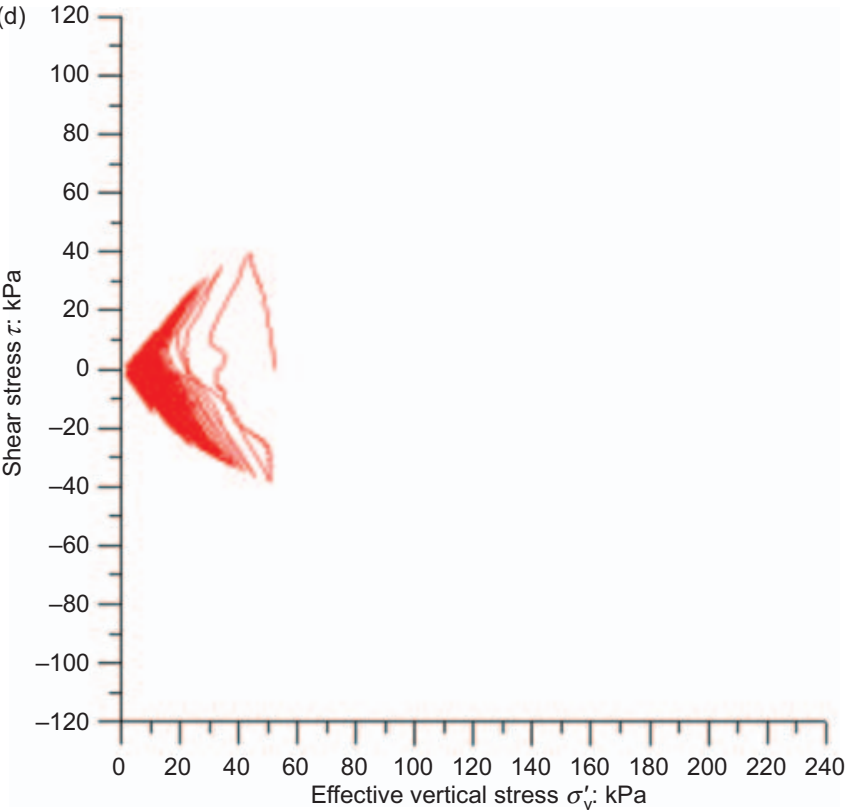

Fig. 7. Cyclic shear response of fibre-reinforced cemented mine tailings under $50 \mathrm{kPa}$ of initial effective vertical stress and $\pm 2 \cdot 5 \%$ of controlled shear strain

\section{FINAL REMARKS}

From the results of a series of monotonic and cyclic simple shear tests on fibre-reinforced cemented mine tailings, the following conclusions can be drawn.

- Under cyclic shear strain controlled load conditions, the increase of initial vertical effective stress increases shear strength.

- The increase of shear strain levels increases the shear stress values achieved in the initial load cycles, to the detriment of the reduced levels of shear stresses for later cycles.

- The composite develops greater strength by deforming more, and the higher the strain level, the greater the damage to the cemented matrix structure. Over successive load cycles, the shear strength decreases gradually and, for the later cycles, is higher for lower strain levels.
For the later cycles, the shear stress values of the fibrereinforced cemented material, for different strain levels, are similar. Disintegration of the cement matrix is compensated for by the existence of fibres that absorb and redistribute the loads.

- The agreement of the same strength envelopes to both monotonic and cyclic stress paths, under different cyclic loading conditions, allows the use of the same strength parameters of mixtures analysed under different loading conditions.

\section{Acknowledgement}

The authors wish to express their gratitude to Brazilian Research Council CNPq/MCT (Project PNPD \#558474/ 2008-0) for financial support. 

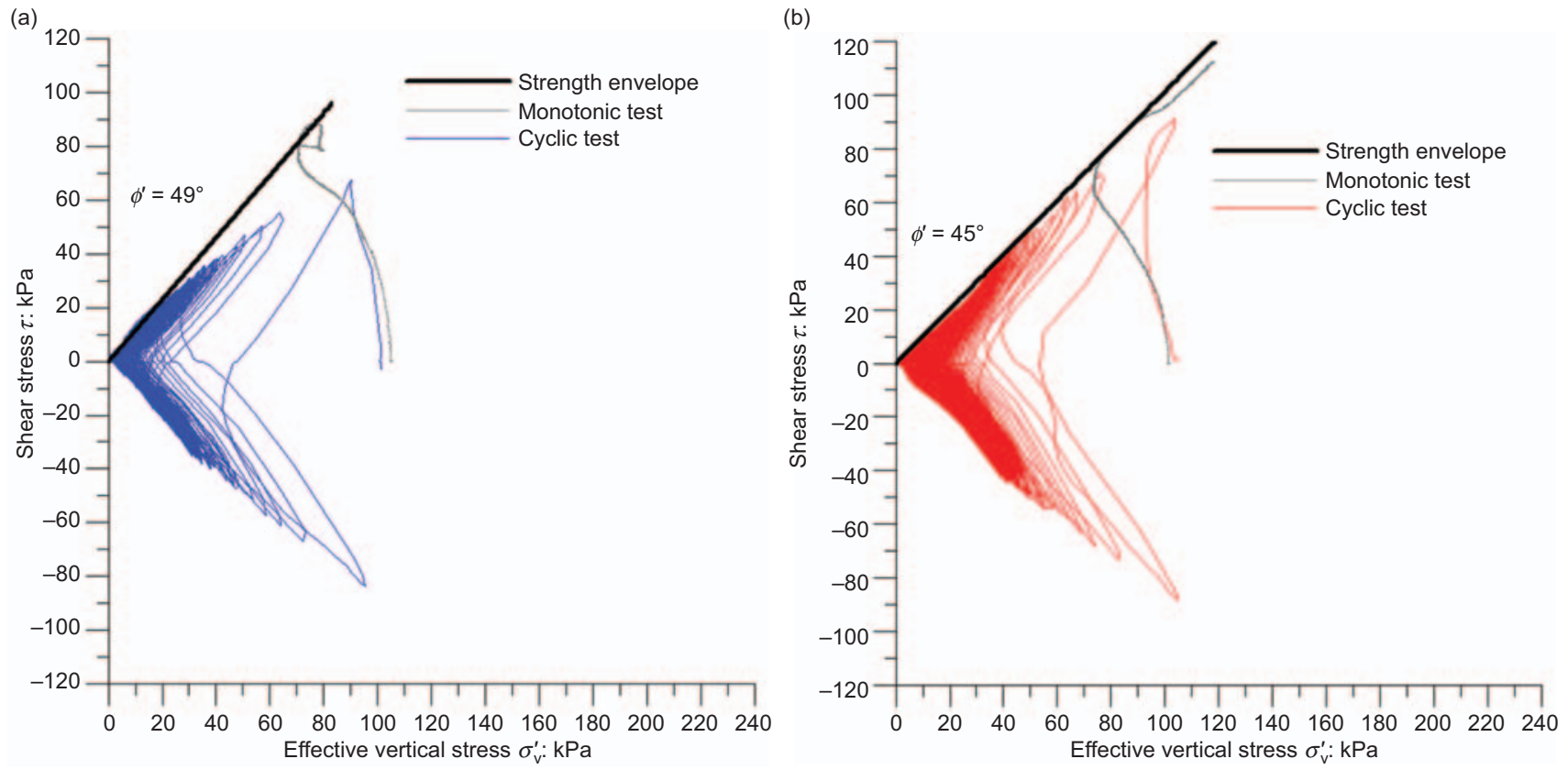

Fig. 8. (a) Strength envelope, shear strain controlled cyclic test $\left(\sigma_{\mathrm{v}}^{\prime}\right.$ initial $\left.=100 \mathrm{kPa}, \gamma= \pm 4 \cdot 5 \%\right)$ and monotonic test $\left(\sigma_{\mathrm{v}}^{\prime}\right.$ initial $=$ $100 \mathrm{kPa})$ stress paths on non-reinforced cemented mine tailings. (b) Strength envelope, shear strain controlled cyclic test $\left(\sigma_{\mathrm{v}}^{\prime}\right.$ initial $=$ $100 \mathrm{kPa}, \gamma= \pm 7 \cdot 0 \%)$ and monotonic test $\left(\sigma_{\mathrm{v}}^{\prime}\right.$ initial $\left.=100 \mathrm{kPa}\right)$ stress paths on fibre-reinforced cemented mine tailings

\section{REFERENCES}

Andresen, A., Berre, T., Kleven, A. \& Lunne, T. (1979). Procedures used to obtain soil parameters for foundation engineering in the North Sea. Marine Geotechnol. 3, No. 3, 201-266.

Arthur, J. R. F., Dunstan, T., Rodriguez del, C. J. I. \& Chua, K. S. (1980). Principal stress rotation: a missing parameter. $J$. Geotech. Engng ASCE 106, No. 4, 419-433.

Consoli, N. C., Montardo, J. P., Donato, M. \& Prietto, P. D. M. (2004). Effect of material properties on the behaviour of sandcement-fibre composites. Ground Improve. 8, No. 2, 77-90.

Consoli, N. C., Foppa, D., Festugato, L. \& Heineck, K. S. (2007). Key parameters for strength control of artificially cemented soils. J. Geotech. Geoenviron. Engng 133, No. 2, 197-205.

Consoli, N. C., Festugato, L. \& Heineck, K. S. (2009). Strainhardening behaviour of fibre-reinforced sand in view of filament geometry. Geosynth. Int. 16, No. 2, 109-115.

Consoli, N. C., Bassani, M. A. \& Festugato, L. (2010a). Effect of fiber-reinforcement on the strength of cemented soils. Geotext. Geomem. 28, No. 4, 344-351.

Consoli, N. C., Cruz, R. C., Floss, M. F. \& Festugato, L. (2010b). Parameters controlling tensile and compressive strength of artificially cemented sand. J. Geotech. Geoenviron. Engng 136, No. 5, 759-763.

Consoli, N. C., Moraes, R. R. \& Festugato, L. (2011a). Split tensile strength of monofilament polypropylene fiberreinforced cemented sandy soils. Geosynth. Int. 18, No. 2, 57-62.

Consoli, N. C., Zortéa, F., Souza, M. \& Festugato, L. (2011b). Studies on the dosage of fiber-reinforced cemented soils. $J$. Mater. Civ. Engng 23, No. 12, 1624-1632.

Consoli, N. C., Thomé, A., Girardello V. \& Ruver, C. A. (2012). Uplift behavior of plates embedded in fiber-reinforced cement stabilized backfill. Geotext. Geomem. 35, 107-111, http://dx. doi.org/10.1016/j.geotexmem.2012.09.002.

Doherty, J. P. \& Fahey, M. (2011). A three-dimensional finite element study of the direct simple shear test. Proc. 2nd Int. Symp. on Frontiers in Offshore Geotechnics, ISFOG2, Perth, Western Australia 1, 341-346.

Helinski, M., Fourie, A. B. \& Fahey, M. (2006). Mechanics of early age cemented paste backfill. Proc. 9th Int. Sem. on Paste and Thickened Tailings, Paste 2006, Limerick, Ireland. Nedlands: Australian Centre for Geomechanics, pp. 313-322.

Helinski, M., Fourie, A. B., Fahey, M. \& Ismail, M. (2007). Assessment of the self-desiccation process in cemented mine backfills. Canad. Geotech. J. 44, No. 10, 1148-1156.

Mao, X. \& Fahey, M. (2003). Behaviour of calcareous soils in undrained cyclic simple shear. Géotechnique 53, No. 8, 715-727.

Mitchell, J. K. (1981). Soil improvement - state-of-the-art report. Proc. 10th Int. Conf. on Soil Mechanics and Foundation Engineering. Stockholm: International Society of Soil Mechanics and Foundation Engineering, pp. 509-565.

Randolph, M. F. \& Wroth, C. P. (1981). Application of the failure state in undrained simple shear shaft capacity of driven piles. Géotechnique 31, No. 1, 143-157.

Skempton, A. W. (1954). The pore-pressure coefficients A and B. Géotechnique 4, No. 4, 143-147.

Vaid, Y. P. \& Finn, W. D. L. (1979). Static shear and liquefaction potential. J. Geotech. Engng ASCE 105, No. 10, 1233-1246.

Wijewickreme, D. \& Vaid, Y. P. (1993). Behaviour of loose sand under simultaneous increase in stress ratio and principal stress rotation. Canad. Geotech. J. 30, No. 6, 953-964.

Wijewickreme, D., Sanin, M. V. \& Greenaway, R. G. (2005). Cyclic shear response of fine-grained mine tailings. Canad. Geotech. J. 42, No. 5, 1408-1421.

\section{WHAT DO YOU THINK?}

To discuss this paper, please email up to 500 words to the editor at journals@ice.org.uk. Your contribution will be forwarded to the author(s) for a reply and, if considered appropriate by the editorial panel, will be published as a discussion. 